\title{
On-Chip Micromachined Dipole Antenna with Parasitic Radiator for mm-Wave Wireless Systems
}

\author{
Mai O. Sallam ${ }^{1}$, Mohamed Serry ${ }^{1}$, Atif Shamim ${ }^{2}$, Sherif Sedky ${ }^{1}$, and Ezzeldin A. Soliman ${ }^{1}$ \\ ${ }^{1}$ The American University in Cairo, AUC Avenue, P. O. Box 74, New Cairo 11835, Egypt \\ ${ }^{2}$ King Abdullah University of Science and Technology, Thuwal, Saudi Arabia
}

\begin{abstract}
In this paper, we present a micromachined dipole antenna with parasitic radiator. The antenna is designed for operation at $60 \mathrm{GHz}$. It consists of two $\lambda_{\mathrm{g}} / 2$ dipole radiators fed by coplanar strips waveguide. Two slightly shorter dipoles are placed in proximity to the main radiators. They act as parasitic dipole arms which increase the bandwidth of the antenna. Two versions of the same antenna topology are presented in this paper in which one uses a high resistivity silicon substrate while the other uses a low resistivity one. The proposed antenna was optimized using HFSS and the final design was simulated using both HFSS and CST for verifying the obtained results. Both simulators are in good agreement. They show that the antenna has very good radiation characteristics where its directivity is around $7.5 \mathrm{dBi}$. The addition of the parasitic arms increased the bandwidth of the antenna from $1.3 \mathrm{GHz}(3.62 \mathrm{GHz})$ to $4.3 \mathrm{GHz}(7.44 \mathrm{GHz})$ when designed on high (low) resistivity silicon substrate.
\end{abstract}

Keywords-micromachined; dipole antenna; millimeter-wave technology; wireless communication

\section{INTRODUCTION}

The $60 \mathrm{GHz}$ band has received much attention in the last few decades where it offers $5 \mathrm{GHz}$ bandwidth [1] which matches the continuous desire of developing small wireless devices that are capable of transmitting data very fast. Thanks to the technology advances, nowadays, devices with dimensions down to the micro and even nanoscale are now fabricated. Different types of antennas at this frequency band have been proposed [2-5] including horn antennas [2], patch antennas, dielectric resonator antennas [45], and many more. Horn antennas have excellent radiation characteristics; however, they are bulky, heavy, and expensive. Patch antennas, on the other hand, are small, light and inexpensive. Nevertheless, they suffer from narrow bandwidth [6]. With the development of integrated circuit technology, the conventional waveguide technology has been gradually replaced in most applications with microwave integrated circuit (MIC) technology [7] and monolithic MIC (MMIC) technology. In these technologies the traditional bulky waveguides and antennas are replaced with planar counterparts. This replacement permits a complete circuit composed of several planar transmission lines and planar antennas, along with many other elements such as diodes and transistors, to be produced together in planar technology on a single substrate holding all the components. The whole circuit can be mass produced in a cost-effective manner by photolithography. In addition to the possibility of a more sophisticated design, planar microwave structures have the advantages of greatly reduced size and weight, higher reliability due to fewer replaceable components, and higher mechanical stability against shocks and vibrations. Moreover, planar antennas can be easily assembled in different array configurations.

In previous work [3], we presented a fabrication process that enables the fabrication of micromachined antennas characterized by their high performance and design simplicity. The idea is based on using only one substrate (silicon substrate in the proposed design) where the antenna is placed on one side of the substrate, while the feeding network is mounted on the other side. Doing so, there is a very good isolation between the antenna and the electronic circuit connected to the transmission lines feeding the antenna. At the same time, the connection between the antenna and its feeding transmission lines is achieved via two Through-Silicon-Vias (TSVs) that penetrate the whole substrate.

This paper is considered an extension for the previous work presented in [3], where we provided a solution to increase the bandwidth of the proposed antenna and maintaining its high radiation performance. This is achieved by adding parasitic radiators of different lengths than the main radiators which results in increasing the bandwidth of the antenna significantly. In this paper, we considered two antenna versions. The first (second) is designed using a high (low) resistivity silicon substrate. The paper is organized as follows: Section II presents the structure of the proposed antenna. A parametric study showing the effect of varying the spacing between the parasitic radiators and the main radiators is presented in section III. The radiation characteristics and the reflection coefficient of the optimum antenna are presented in section IV. The important conclusions are summarized in section V.

\section{Structure of THE Proposed ANTENNA}

Fig. 1 shows the structure of the proposed antenna. It consists of two main radiators, each of which is $\lambda_{\mathrm{g}} / 2$ length. The radiators are made of copper and are placed on top of very thin silicon walls. Their feeding is achieved via coupled strips (CPS) feeding lines which are made of copper and are located at the backside of the substrate. The connection between the radiators and the feeding lines are achieved via two Through- Silicon-Vias (TSVs), which are filled with copper. Copper layer is placed around the silicon walls which act as a ground plane that prevents radiation from the back side of the substrate. Two parasitic radiators on top of silicon walls are placed close to the main radiators. 
They have slightly smaller length than the main ones. These parasitic radiators are added to create another resonance in the frequency band leading to an overall wider antenna bandwidth. It is worth mentioning that the feeding lines are further extended after the TSV, as seen in Fig. 1(b) which acts as a stub in order to enhance the matching between the antenna and the $50 \Omega$ feeding CPS lines.

In this paper, two versions of the same antenna topology are proposed. The first is designed on high resistivity silicon substrate $(\rho s i \geq 2,000 \Omega . \mathrm{cm})$ while the other is designed on low-resistivity silicon substrate ( $\rho \mathrm{si}=45 \Omega \mathrm{cm}$ ). In the first case, the antenna has better radiation performance while in the second case; the design is more compatible with the electronic devices. The main antenna parameters are shown in Fig. 1(c). It is worth mentioning that the proposed design has been optimized under supervision over the following parameters: $L_{\text {driv }}, W_{\text {driv }}, L_{\text {para }}, W_{\text {para, }}$ and $S_{\text {para }}$ in order to get the maximum possible bandwidth. The rest of parameters do not have significant effect on the location of the resonance frequencies and thus they have been excluded from the optimization process. The parameters $L_{s t u b}, W_{s t u b}$, and $S_{s t u b}$ are the parameters which mainly determine the level of matching between the antenna and the feeding CPS lines.

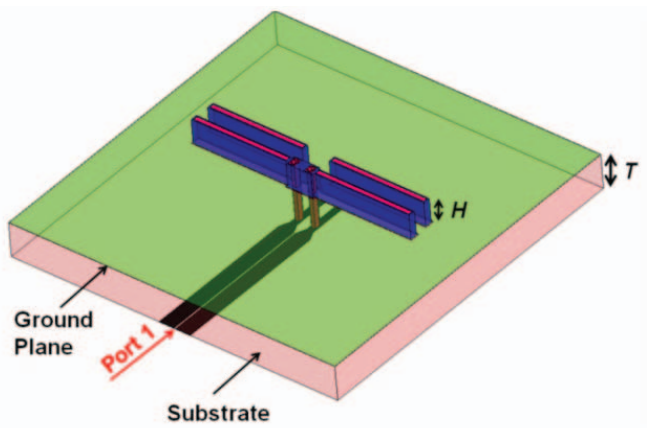

(a)

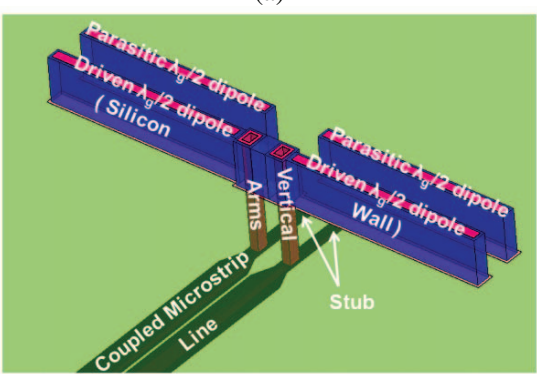

(b)

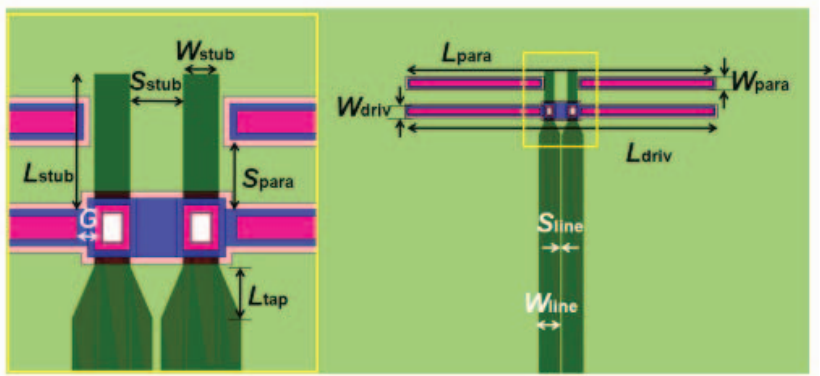

(c)

Fig. $13 \mathrm{D}$ structure of the linearly polarized antenna with parasitic elements (a) zoom-out view, (b) zoom-in view, (c) top-view.

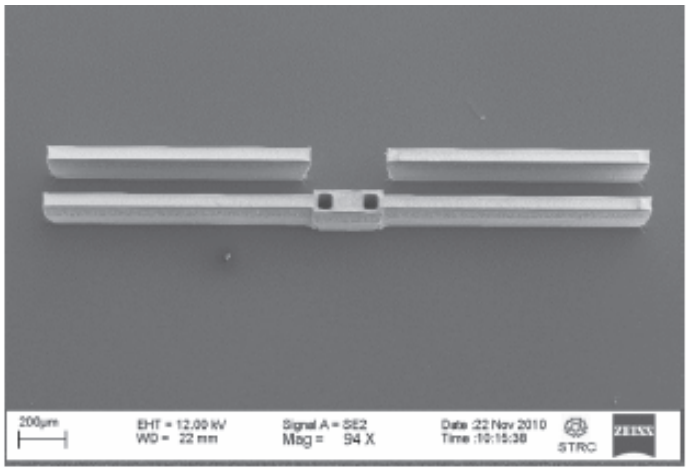

Fig. 2. SEM image of the fabricated linearly polarized micromachined antenna with parasitic elements.

TABLE I

OPTIMUM GEOMETRICAL PARAMETERS OF THE LINEARLY POLARIZED MICROMACHINED ANTENNA WITH PARASITIC ELEMENTS

\begin{tabular}{|c|c|}
\hline $\begin{array}{c}\text { Antenna Geometrical } \\
\text { Parameters }\end{array}$ & $\begin{array}{c}\text { On either High- or Low-Resistivity } \\
\text { Silicon }\end{array}$ \\
\hline$H$ & $275 \mu \mathrm{m}$ \\
\hline$T$ & $400 \mu \mathrm{m}$ \\
\hline$L$ driv & $2.67 \mathrm{~mm}$ \\
\hline$W_{\text {driv }}$ & $80 \mu \mathrm{m}$ \\
\hline$G$ & $40 \mu \mathrm{m}$ \\
\hline$L$ para & $2.65 \mathrm{~mm}$ \\
\hline$W_{\text {para }}$ & $80 \mu \mathrm{m}$ \\
\hline$S_{\text {para }}$ & $155 \mu \mathrm{m}$ \\
\hline$L_{\text {tap }}$ & $115 \mu \mathrm{m}$ \\
\hline$L_{\text {stub }}$ & $305 \mu \mathrm{m}$ \\
\hline$W_{\text {stub }}$ & $80 \mu \mathrm{m}$ \\
\hline$S_{\text {stub }}$ & $120 \mu \mathrm{m}$ \\
\hline$W_{\text {line }}$ & $180 \mu \mathrm{m}$ \\
\hline$S_{\text {line }}$ & $20 \mu \mathrm{m}$ \\
\hline
\end{tabular}

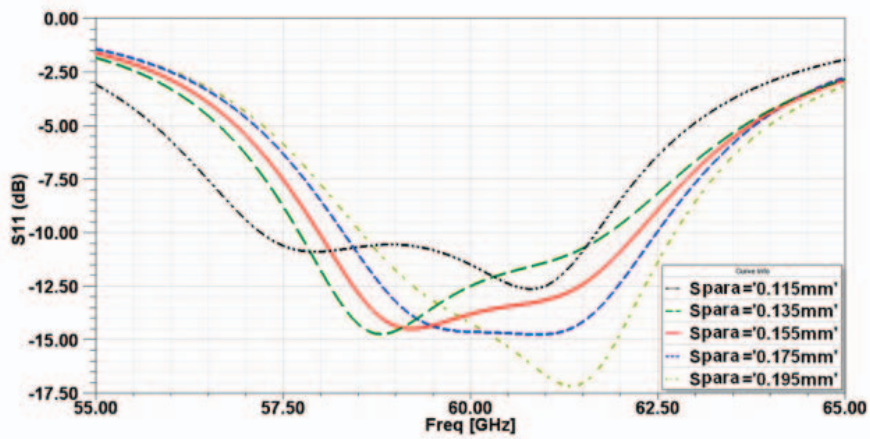

(a)

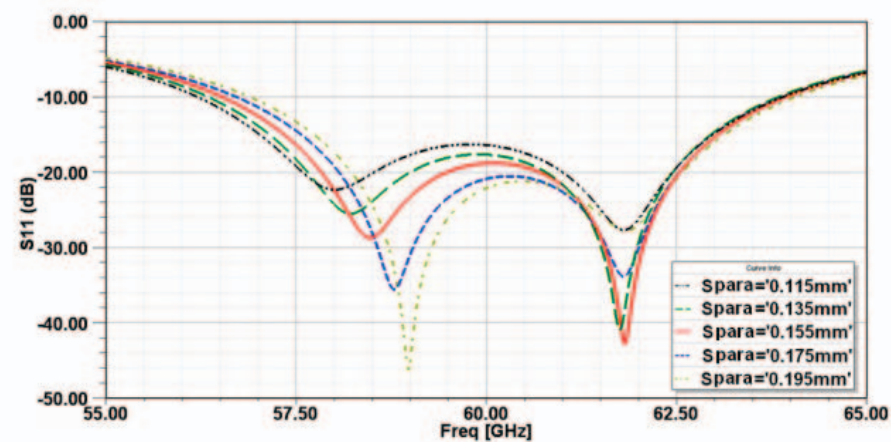

(b)

Fig. 3 Return loss versus frequency for different values of Spara: (a) on highresistivity silicon, and (b) on low-resistivity silicon. 


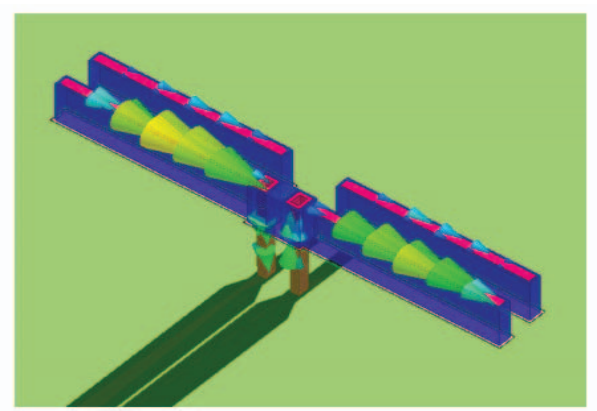

Fig. 4 Current distribution along the main and parasitic radiators.

The geometrical dimensions of the optimized linearly polarized micromachined antenna with parasitic elements are listed in Table 1. The SEM image of the fabricated prototype of the proposed antenna is shown in Fig. 2. It is clear that antenna has very sharp walls.

\section{PARAMETRIC STUDY}

The geometrical design parameters of the proposed antenna can be classified into three groups $\left(L_{\text {driv }}, W_{\text {driv }}, G\right)$, $\left(L_{\mathrm{para}}, W_{\mathrm{para}}\right)$ and $\left(S_{\mathrm{para}}\right)$. The first (second) group that belongs to the driven (parasitic) element is affecting the lower (higher) resonance frequency. As the length/width increases, the corresponding resonance shifts to lower frequencies. It is important to make the length of the parasitic element close to that of the main radiators such that the two obtained resonances are close to each other and result in an overlapping bandwidth. As for the spacing between the two elements, $\left(S_{\text {para }}\right)$, increasing its value results in reducing the mutual capacitance between the radiators. This results in decreasing the overall capacitance in the equivalent resonance circuit representing the antenna. Consequently, the resonance frequency increases and the return loss curve shifts to the right as shown in Fig. 3.

TABLE II

COMPARISON BETWEEN THE RADIATION CHARACTERISTICS OF THE LINEARLY POLARIZED ANTENNA WITH AND WITHOUT PARASITIC RADIATORS

\begin{tabular}{|c|c|c|c|c|}
\hline \multirow{2}{*}{$\begin{array}{c}\text { Antenna } \\
\text { characteristics }\end{array}$} & \multicolumn{2}{|c|}{ No Parasitic Elements } & \multicolumn{2}{|c|}{ With Parasitic Elements } \\
\hline & High Res. & Low Res. & High Res. & Low Res. \\
\hline $\begin{array}{l}\text { Impedance } \\
\text { Bandwidth } \\
(-10 \mathrm{~dB})\end{array}$ & $\begin{array}{c}1.30 \mathrm{GHz} \\
(2.16 \%)\end{array}$ & $\begin{array}{c}3.62 \mathrm{GHz} \\
\quad(6 \%)\end{array}$ & $\begin{array}{c}4.30 \mathrm{GHz} \\
(7.16 \%)\end{array}$ & $\begin{array}{c}7.44 \mathrm{GHz} \\
(12.4 \%)\end{array}$ \\
\hline Directivity & $7.87 \mathrm{dBi}$ & $7.81 \mathrm{dBi}$ & $7.49 \mathrm{dBi}$ & $7.56 \mathrm{dBi}$ \\
\hline $\begin{array}{l}\text { Radiation } \\
\text { Efficiency }\end{array}$ & $94.10 \%$ & $35.6 \%$ & $94.13 \%$ & $34.4 \%$ \\
\hline Gain & $7.61 \mathrm{dBi}$ & $3.33 \mathrm{dBi}$ & $7.23 \mathrm{dBi}$ & $2.92 \mathrm{dBi}$ \\
\hline $\begin{array}{l}\text { Maximum } \\
\text { Cross } \\
\text { Polarization } \\
\text { Level (E-plane) }\end{array}$ & $-27.53 \mathrm{~dB}$ & $-26.15 \mathrm{~dB}$ & $-23.12 \mathrm{~dB}$ & $-20.24 \mathrm{~dB}$ \\
\hline $\begin{array}{l}\text { Maximum } \\
\text { Cross } \\
\text { Polarization } \\
\text { Level ( } H \text {-plane })\end{array}$ & $-37.30 \mathrm{~dB}$ & $-25.98 \mathrm{~dB}$ & $-40.66 \mathrm{~dB}$ & $-41.37 \mathrm{~dB}$ \\
\hline $\begin{array}{l}\text { Front-to-Back } \\
\text { Ratio }\end{array}$ & $15.15 \mathrm{~dB}$ & $12.44 \mathrm{~dB}$ & $17.17 \mathrm{~dB}$ & $18.88 \mathrm{~dB}$ \\
\hline $\begin{array}{l}\text { Communication } \\
\text { Range }\left(\mathrm{PT}_{\mathrm{x}}=\right. \\
10 \mathrm{dBm} \text { and } \\
\mathrm{PRx}_{\mathrm{x}}=-70 \\
\mathrm{dBm})\end{array}$ & $22.96 \mathrm{~m}$ & $8.57 \mathrm{~m}$ & $21.03 \mathrm{~m}$ & $7.80 \mathrm{~m}$ \\
\hline
\end{tabular}

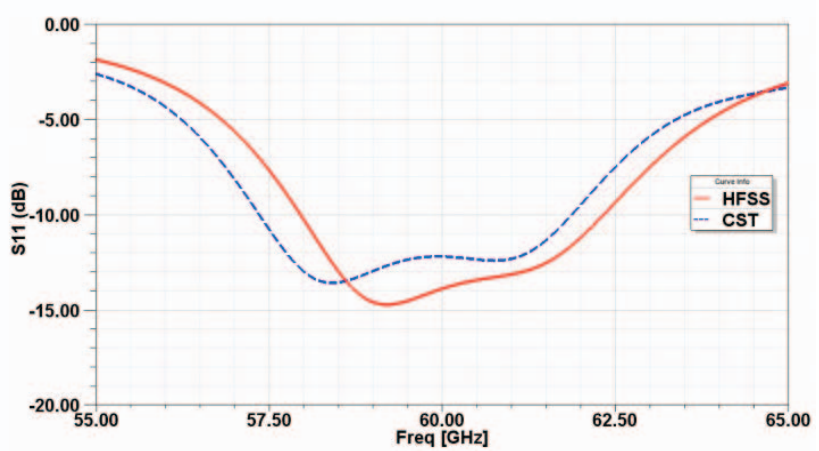

(a)

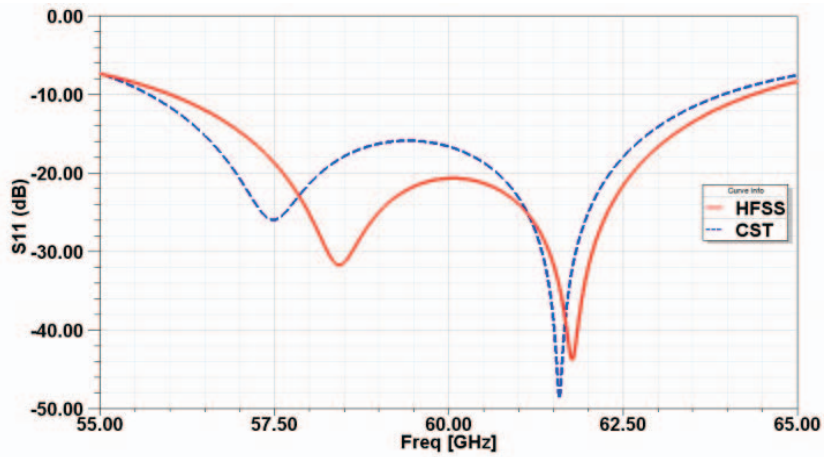

(b)

Fig. 5. Reflection coefficient versus frequency for the proposed antenna: (a) high resistivity, and (b) low resistivity silicon substrate.

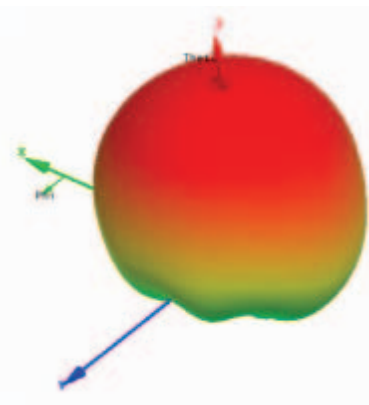

(a)

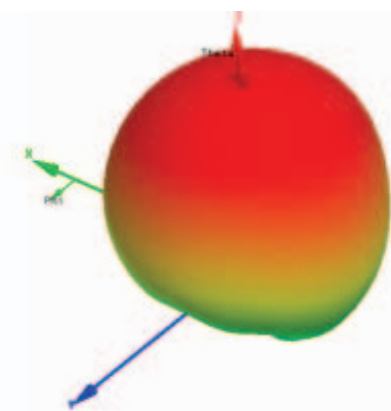

(b)
Fig. 6. 3D radiation pattern of the proposed antenna on (a) high-resistivity, and (b) low-resistivity silicon substrate.

\section{RESULTS AND DISCUSSION}

The antenna operates by exciting the differential mode of the CPS transmission line. The current along the two metals of the transmission lines becomes out of phase. Similarly currents along the TSVs are out of phase and cause no radiation. On the other hand, the currents along the main radiators are in the same direction, as shown in Fig. 4. Due to the small distance between the main radiators and the parasitic ones, electromagnetic coupling takes place leading to current flowing along them. The optimized antennas have been simulated using both HFSS and CST in order to verify the obtained results. 


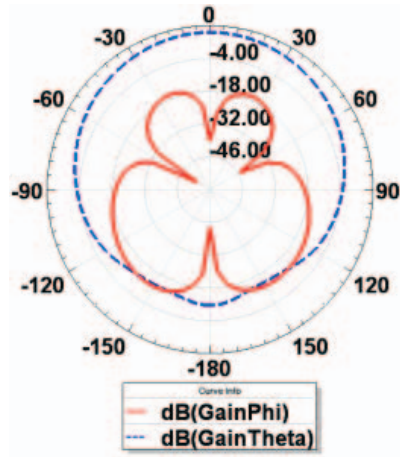

(a)

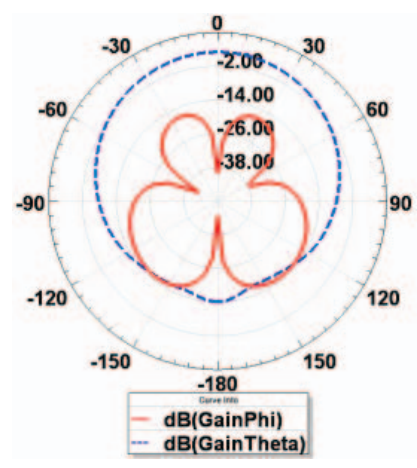

(c)

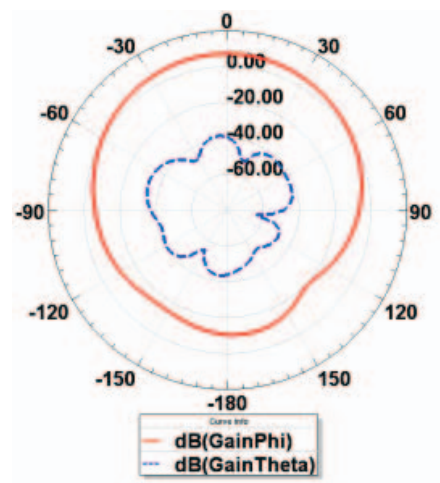

(b)

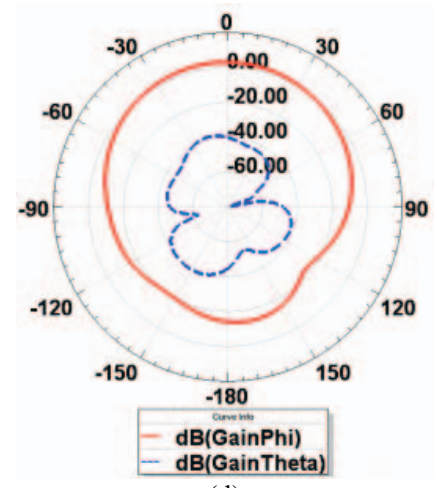

(d)
Fig. 7. Radiation patterns in two orthogonal planes of the linearly polarized micromachined antenna with parasitic elements at $60 \mathrm{GHz}$ on low-resistivity silicon: (a) $\mathrm{Phi}=0^{\circ}$, and (b) $\mathrm{Phi}=90^{\circ}$.

Fig. 5 shows the return loss of the antenna versus frequency. From the figure, HFSS shows that the antenna is resonating at $59 \mathrm{GHz}$ and $61.5 \mathrm{GHz}(58.5 \mathrm{GHz}$, and $62 \mathrm{GHz})$, when using high (low) resistivity silicon substrate. CST shows similar behavior for the reflection coefficient with a small shift in the resonance frequencies. However, this small shift in frequency is acceptable. Fig. 6 shows the 3D radiation patterns of this antenna at $60 \mathrm{GHz}$ as calculated using HFSS. These figures demonstrate that the antenna is mainly radiating in the front-side with negligible radiation in the back-side due to the presence of the ground plane. This results in having minimum interference with the driving circuit which is located at the back-side of the substrate, as was mentioned earlier.

The electric characteristics of the linearly polarized micromachined antenna with and without parasitic radiators are all listed in Table II as simulated by HFSS. The antenna demonstrates its high radiation performance where its directivity is above $7 \mathrm{dBi}$. The radiation efficiency for the high-resistivity version is above $90 \%$, while for the low resistivity silicon the radiation efficiency drops to $30 \%-40 \%$. This decrease is due to the losses inside the low-resistivity substrate. As clear from Table II, the proposed antennas have very high polarization purity at both the $E$ - and $H$ - planes. This is of great benefit to communication systems as it enables doubling the system capacity. As for the communication range, the calculations presented in Table II was based on Frizz formula given by:

$$
\frac{P_{t}}{P_{r}}=\left(\frac{\lambda_{0}}{4 \pi R}\right)^{2} G_{t} G_{r}
$$

where $P_{t}$ is the input power at the terminals of the transmitting antenna, $P_{r}$ is the amount of power collected by the receiving antenna, $\lambda_{0}$ is the free-space wavelength, $R$ is the distance between the transmitting and receiving antennas. $G_{t}$ and $G_{r}$ are the gains of the transmitting and receiving antennas, respectively, which assumed to be identical. For all the proposed antennas, the transmitted power used for calculation is $10 \mathrm{dBm}$ while the receiver sensitivity is $-70 \mathrm{dBm}$.

\section{CONCLUSION}

In this paper, a linearly polarized micromachined antenna with parasitic elements was introduced. The antenna operates at $60 \mathrm{GHz}$. This antenna is considered extension for previous work, where two parasitic elements in proximity to the main radiators were added in order to increase the antenna's operating bandwidth. Two versions have been studied, when using high resistivity and low resistivity silicon substrates. Comparing the results obtained for the linearly polarized antenna (with and without parasitic elements), it is obvious that both designs have similar radiation characteristics. However, the addition of the parasitic elements greatly enhanced the bandwidth.

\section{REFERENCES}

[1] B. L. Dang, R. V. Prasad, I. Niemegeers, and M. G. Larrode, “ Toward a seamless communication architecture for in-building networks at 60 GHz band," $31^{\text {st }}$ IEEE conf. Local Comp. Networks, Nov. 2006.

[2] B. Pan, Y. Li, G. E. Ponchak, and M. M. Tentzeris, "A 60-GHz CPWfed high-gain and broadband integrated horn antenna," IEEE Trans. Ant. Propag., vol 57, no. 4, pp. 1050-1056, April 2009.

[3] M. O. Sallam, E. A. Soliman, and S. Sedky, " Novel linearly and circularly polarized $60 \mathrm{GHz}$ MEMS antennas on low- and highresistivity silicon," $5^{\text {th }}$ European Conf. Antenn. Propag, pp.1194-1198, April 2011.

[4] Q. Lai, C. Fumeaux, W. Hong, and R. Vahdieck, "60 GHz aperturecoupled dielectric resonator antennas fed by a half-mode substrate integrated waveguide," IEEE Trans. Ant. Propag., vol. 58, no.6, pp.1856-1864, March 2010.

[5] M. O. Sallam, M. Serry, S. Sedky, A. Shamim, W. De Raedt, G. A. E. Vandenbosch, and E. A. Soliman, "Micromachined on-chip dielectric resonator antenna operating at $60 \mathrm{GHz}, "$ IEEE Trans. Ant. Propag., vol. 63, no. 8, pp. 3410-3416, August 2015.

[6] S. E. Mendhe, and Y. P. Kosta, "Broadband Multilayer Stacked Rectangular Microstrip Patch Antenna Using Edge Coupled Patches," $2^{\text {nd }}$ International Conference on Emerging Technology Trends in Electronics, Communication and Networking (ET2ECN), 2014.

[7] A K. Jayaraj, Thomas E. Noll, and D. R. Singh, A Low Cost Multichip Packaging Technology for Monolithic Microwave Integrated Circuits," IEEE Trans Ant. Propag., vol. 43, no. 9, 2005. 